\title{
A growing threat to the ozone layer from short-lived anthropogenic chlorocarbons
}

\author{
David E. Oram ${ }^{1,2}$, Matthew J. Ashfold ${ }^{3}$, Johannes C. Laube ${ }^{2}$, Lauren J. Gooch ${ }^{2}$, Stephen Humphrey ${ }^{2}$, \\ William T. Sturges ${ }^{2}$, Emma Leedham-Elvidge ${ }^{2,8}$, Grant L. Forster ${ }^{1,2}$, Neil R. P. Harris ${ }^{4}$, Mohammed Iqbal Mead ${ }^{4,5}$, \\ Azizan Abu Samah ${ }^{5}$, Siew Moi Phang ${ }^{5}$, Chang-Feng Ou-Yang ${ }^{6}$, Neng-Huei Lin ${ }^{6}$, Jia-Lin Wang ${ }^{7}$, Angela K. Baker ${ }^{8}$, \\ Carl A. M. Brenninkmeijer ${ }^{8}$, and David Sherry ${ }^{9}$ \\ ${ }^{1}$ National Centre for Atmospheric Science, School of Environmental Sciences, University of East Anglia, \\ Norwich, NR4 7TJ, UK \\ ${ }^{2}$ Centre for Ocean and Atmospheric Sciences, School of Environmental Sciences, University of East Anglia, Norwich, UK \\ ${ }^{3}$ School of Environmental and Geographical Sciences, University of Nottingham Malaysia Campus, \\ 43500 Semenyih, Malaysia \\ ${ }^{4}$ Centre for Atmospheric Informatics and Emissions Technology, School of Energy, Environment and \\ Agrifood/Environmental Technology, Cranfield University, Cranfield, UK \\ ${ }^{5}$ Institute of Ocean and Earth Sciences, University of Malaya, Kuala Lumpur, Malaysia \\ ${ }^{6}$ Department of Atmospheric Sciences, National Central University, Taoyuan, Taiwan \\ ${ }^{7}$ Department of Chemistry, National Central University, Taoyuan, Taiwan \\ ${ }^{8}$ Max Planck Institute for Chemistry, Air Chemistry Division, Mainz, Germany \\ ${ }^{9}$ Nolan Sherry \& Associates, Kingston upon Thames, London, UK
}

Correspondence to: David E. Oram (d.e.oram@uea.ac.uk)

Received: 25 May 2017 - Discussion started: 2 June 2017

Revised: 12 September 2017 - Accepted: 14 September 2017 - Published: 12 October 2017

\begin{abstract}
Large and effective reductions in emissions of long-lived ozone-depleting substance (ODS) are being achieved through the Montreal Protocol, the effectiveness of which can be seen in the declining atmospheric abundances of many ODSs. An important remaining uncertainty concerns the role of very short-lived substances (VSLSs) which, owing to their relatively short atmospheric lifetimes (less than 6 months), are not regulated under the Montreal Protocol. Recent studies have found an unexplained increase in the global tropospheric abundance of one VSLS, dichloromethane $\left(\mathrm{CH}_{2} \mathrm{Cl}_{2}\right)$, which has increased by around $60 \%$ over the past decade. Here we report dramatic enhancements of several chlorine-containing VSLSs (Cl-VSLSs), including $\mathrm{CH}_{2} \mathrm{Cl}_{2}$ and $\mathrm{CH}_{2} \mathrm{ClCH}_{2} \mathrm{Cl}$ (1,2-dichloroethane), observed in surface and upper-tropospheric air in East and South East Asia. Surface observations were, on occasion, an order of magnitude higher than previously reported in the marine boundary layer, whilst upper-tropospheric data were up to 3 times higher than expected. In addition, we pro-
\end{abstract}

vide further evidence of an atmospheric transport mechanism whereby substantial amounts of industrial pollution from East Asia, including these chlorinated VSLSs, can rapidly, and regularly, be transported to tropical regions of the western Pacific and subsequently uplifted to the tropical upper troposphere. This latter region is a major provider of air entering the stratosphere, and so this mechanism, in conjunction with increasing emissions of Cl-VSLSs from East Asia, could potentially slow the expected recovery of stratospheric ozone.

\section{Introduction}

Large-scale ozone depletion in the stratosphere is a persisting global environmental problem. It is predominantly caused by the release of reactive chlorine and bromine species from halogenated organic compounds. Although the basic science is well established, there remains significant uncertainty sur- 
rounding the long-term recovery of the ozone layer (Hegglin et al., 2015). One important issue is the recent, unexplained increase in the global tropospheric abundance of dichloromethane $\left(\mathrm{CH}_{2} \mathrm{Cl}_{2}\right)$, which has increased by $\sim 60 \%$ over the past decade (Leedham-Elvidge et al., 2015; Hossaini et al., 2015a; Carpenter et al., 2015). $\mathrm{CH}_{2} \mathrm{Cl}_{2}$ is one of a large group of halogenated compounds known as VSLSs (very short-lived substances). Owing to their relatively short atmospheric lifetimes (typically less than 6 months) and their correspondingly low ozone depletion potentials (ODPs), VSLSs are not currently regulated by the Montreal Protocol. It is however estimated that a significant fraction of VSLSs and their atmospheric degradation products reach the stratosphere ( $>80 \%$ in the case of chlorinated VSLSs; Carpenter et al., 2015), and, furthermore, halogenated VSLSs have been shown to have a disproportionately large impact on radiative forcing and climate due to their atmospheric breakdown and the subsequent depletion of ozone, occurring at lower, climate-sensitive altitudes (Hossaini et al., 2015b). According to the most recent Scientific Assessment of Ozone Depletion (Carpenter et al., 2015) over the period 2008-2012, the total chlorine from VSLSs increased at a rate of approximately $1.3 \pm 0.2 \mathrm{ppt} \mathrm{Cl} \mathrm{yr}^{-1}$, the majority of this increase being due to $\mathrm{CH}_{2} \mathrm{Cl}_{2}$, and this has already begun to offset the decline in total tropospheric chlorine loading over the same period (13.4 $\left.\pm 0.9 \mathrm{ppt} \mathrm{Cl} \mathrm{yr}^{-1}\right)$ caused by the reduced emissions of substances controlled by the Montreal Protocol.

In recent years much attention has been focussed on the potential of bromine-containing VSLSs to contribute to stratospheric ozone depletion (Law et al., 2007; Montzka et al., 2011). This is primarily due to the large observed discrepancy between the measured inorganic bromine in the stratosphere and the amount of bromine available from known, longer-lived source gases, namely the halons and methyl bromide (Dorf et al., 2006). In contrast, the role of very shortlived chlorine compounds (Cl-VSLSs) in ozone depletion has been considered relatively minor because they are believed to contribute only a few percent to the total chlorine input to the stratosphere, the majority of which is supplied by long-lived compounds such as the chlorofluorocarbons (CFCs), methyl chloroform $\left(\mathrm{CH}_{3} \mathrm{CCl}_{3}\right)$, and carbon tetrachloride $\left(\mathrm{CCl}_{4}\right)$. Since 1987 the consumption of these longlived anthropogenic compounds has been controlled by the Montreal Protocol, and the sum of total organic chlorine in the troposphere has been falling since its peak of around 3660 parts per trillion (ppt) in 1993/1994 to $\sim 3300 \mathrm{ppt}$ in 2012 (Carpenter et al., 2015). Because of its relatively short atmospheric lifetime ( $\sim 5$ years) and its high chlorine content (3 chlorine atoms per molecule), the main contributor to this decline has been $\mathrm{CH}_{3} \mathrm{CCl}_{3}$. However, most $\mathrm{CH}_{3} \mathrm{CCl}_{3}$ has now been removed from the atmosphere with a presentday abundance of less than 5 ppt. Consequently, the rate of decline in total organic chlorine has fallen to $13.4 \mathrm{ppt} \mathrm{yr}^{-1}$ (2008-2012), which is around $50 \%$ smaller than the maximum seen in the late 1990s (Carpenter et al., 2015).

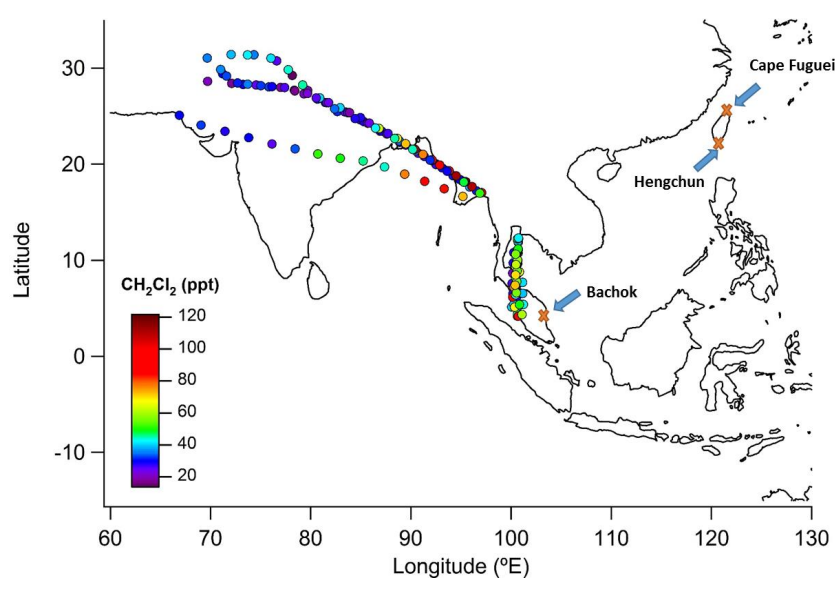

Figure 1. Map of the region showing the location of each CARIBIC sample. The markers have been coloured according to their $\mathrm{CH}_{2} \mathrm{Cl}_{2}$ concentration to highlight the regions where enhanced levels of VSLSs were observed. Also shown are the approximate locations of the three surface stations (orange crosses).

Owing to their short atmospheric lifetimes and their hitherto low background concentrations, chlorinated VSLSs have not been considered of major importance for ozone depletion. Indeed the contribution of VSLSs to the total chlorine entering the stratosphere is estimated to be only 55 (3895) ppt (Carpenter et al., 2015), which is between 1 and $3 \%$ of the present-day (2012) total (3300 ppt). However, because of their short lifetimes, the potential impact of VSLSs on stratospheric ozone is highly dependent on the location of their sources, with emissions close to the major stratospheric input regions being of far greater significance for ozone depletion (Brioude et al., 2010; Pisso et al., 2010).

The transport of trace gases and aerosols from the troposphere into the stratosphere occurs primarily in the tropics, where convective activity and vertical uplift are most intense. In order to get to the stratosphere, an air parcel has to pass through the tropical tropopause layer (TTL), the region of the atmosphere between the level of maximum convective outflow ( $\sim 12 \mathrm{~km}$ altitude, $345 \mathrm{~K}$ potential temperature) and the cold-point tropopause $(\sim 17 \mathrm{~km}, 380 \mathrm{~K}$ ) (see Box $1-3$, Fig. 1 in Carpenter et al., 2015). The vertical flux into the TTL is thought to be dominated by two main regional pathways: (1) ascent above the western Pacific during Northern Hemispheric (NH) winter and (2) the circulation of the Asian (Indian) Monsoon during NH summer (Fueglistaler et al., 2005; Randel et al., 2010; Bergman et al., 2012; Haines et al., 2014). The latter has been suggested as the most important region for the transport of anthropogenic pollution (Randel et al., 2010).

Because of their short lifetimes, to be able to accurately determine the VSLS contribution to total organic halogen loading in the stratosphere, it is highly desirable to collect data in the TTL. Surface measurements alone, particularly in 
regions outside the tropics where most long-term surface stations are sited, are not sufficient. Furthermore, because of the distribution and seasonality of stratospheric entry points, it is also essential to measure in specific locations and at specific times of year, i.e. in the Indian summer monsoon and over the winter western Pacific. Unfortunately there are very few available measurements of VSLSs in the TTL generally as it is above the maximum altitude of most research aircraft, and, furthermore, there is a paucity of both ground and aircraft data available in these two key regions of interest. Where recent TTL data are available it is primarily from different regions and focussed on brominated VSLSs (e.g. Sala et al., 2014; Navarro et al., 2015).

The focus of the present study is the western Pacific and, in particular, the region of the South China Sea. During $\mathrm{NH}$ winter the region is heavily influenced by the large anticyclone that forms over Siberia each year, which gives rise to strong north-easterly winds that impact deep into the tropics as far south as Malaysia, Singapore, and Indonesia. These north-easterly winds typically prevail for 4-5 months (November-March) and form part of the East Asian winter monsoon circulation. Superimposed on this seasonal synoptic flow are transient disturbances known as cold surges, which are triggered by a southward shift of the anticyclone and lead to sudden drops in surface air temperatures and increased wind speeds (Zhang et al., 1997; Garreaud, 2001). It has been proposed that during these events significant amounts of pollution from continental East Asia $\left(>35^{\circ} \mathrm{N}\right)$ can be transported rapidly to the tropics (Ashfold et al., 2015). Furthermore, these events, which can last for many days, occur regularly each winter and are associated with some of the strongest convective activity in the western Pacific region. Indeed, trajectory calculations show that it can take less than 10 days for air masses to travel from the East Asian boundary layer $\left(>35^{\circ} \mathrm{N}\right)$ to the upper tropical troposphere (altitudes $>200 \mathrm{hPa}$ ), thereby providing a fast route by which VSLSs (and many other pollutants) may enter the lower stratosphere, despite their relatively short atmospheric lifetimes (Ashfold et al., 2015).

Here we provide strong evidence to support this proposed transport mechanism based on new atmospheric observations in the East and SE Asia region. We will present new Cl-VSLS measurements from recent ground-based and aircraft campaigns in the region during which we have observed dramatic enhancements in a number of Cl-VSLSs, including $\mathrm{CH}_{2} \mathrm{Cl}_{2}, 1,2$ dichloroethane $\left(\mathrm{CH}_{2} \mathrm{ClCH}_{2} \mathrm{Cl}\right)$, trichloromethane $\left(\mathrm{CHCl}_{3}\right)$, and tetrachloroethene $\left(\mathrm{C}_{2} \mathrm{Cl}_{4}\right)$. Furthermore, we will demonstrate how pollution from China and the surrounding region can rapidly, and regularly, be transported across the South China Sea and subsequently uplifted to altitudes of 11-12 km, the region close to the lower TTL. Using the NAME (Numerical Atmospheric-dispersion Modelling Environment) particle dispersion model, we will also investigate the origin of the observed Cl-VSLSs and examine the fre- quency and duration of cold surge events. Finally we present some new estimates of $\mathrm{CH}_{2} \mathrm{Cl}_{2}$ emissions from East Asia and use these to estimate the likely emissions of $\mathrm{CH}_{2} \mathrm{ClCH}_{2} \mathrm{Cl}$, for which there is little information in the recent literature.

\section{Methods}

Between 2012 and 2014, air samples were collected at various times (1) two coastal sites in Taiwan - Hengchun $\left(22.0547^{\circ} \mathrm{N}, 120.6995^{\circ} \mathrm{E}\right)$ and Fuguei Cape $\left(25.297^{\circ} \mathrm{N}\right.$, $\left.121.538^{\circ} \mathrm{E}\right)$; (2) at the Bachok Marine Research Station on the north-east coast of Peninsular Malaysia $\left(6.009^{\circ} \mathrm{N}\right.$, $102.425^{\circ} \mathrm{E}$ ); and (3) during several flights of the IAGOSCARIBIC aircraft between Germany and Thailand or Malaysia. IAGOS-CARIBIC is a European project making regular measurements from an in-service passenger aircraft operated by Lufthansa (Airbus A340-600; Brenninkmeijer et al., 2007; http://www.caribic-atmospheric.com/).

A total of 21 samples were collected at Hengchun between 7 March and 5 April 2013 with a further 22 samples taken at Cape Fuguei between 11 March and 4 April 2014. Overall, 28 samples were collected at Bachok between 20 January and 5 February 2014, during the period of the NE winter monsoon. The approximate location of each surface site is shown in Fig. 1. The CARIBIC aircraft samples were collected during seven return flights between (i) Frankfurt (Germany) and Bangkok (Thailand) and (ii) Bangkok and Kuala Lumpur (Malaysia) during the periods December 2012-March 2013 (four flights) and November 2013January 2014 (three flights). All CARIBIC flights in this region between December 2012 and January 2014 have been included in this analysis. With the exception of three samples that were taken at altitudes between 8.5 and $9.8 \mathrm{~km}$, the CARIBIC samples were all $(n=179)$ collected at altitudes between 10 and $12.3 \mathrm{~km}$.

\subsection{Sample collection}

Air samples from Taiwan and Malaysia were collected in 3.2 L silco-treated stainless steel canisters (Restek) at a pressure of approximately 2 bar using a battery-powered diaphragm pump (Air Dimensions, B series). In Taiwan the samples were collected from the surface via a $1 \mathrm{~m} \times 1 / 4^{\prime \prime}$ OD Dekabon sampling line, whilst in Bachok the samples were collected from the top of an $18 \mathrm{~m}$ tower via a $5 \mathrm{~m} \times 1 / 4^{\prime \prime}$ OD Dekabon sampling line. In both cases the tubing was flushed for at least $5 \mathrm{~min}$ prior to sampling. The sampling integrity was confirmed by sampling high-purity air (BTCA178, BOC) through the inlet tubing and pump. Samples were collected within $50 \mathrm{~m}$ of the sea and only when the prevailing winds were from the sea, minimising the impact of any local emissions. The CARIBIC aircraft samples were collected in $2.7 \mathrm{~L}$ glass flasks at a pressure of 4.5 bar using a two-stage 
metal bellows pumping system (Brenninkmeijer et al., 2007; Baker et al., 2010).

\subsection{Sample analysis}

The collected air samples were shipped to UEA (University of East Anglia) and analysed for their halocarbon content by gas chromatography-mass spectrometry (GC-MS) following trace gas enrichment using previously published methods. All samples (i.e. Taiwan, Bachok, and CARIBIC) were analysed for $\mathrm{CH}_{2} \mathrm{Cl}_{2}, \mathrm{CHCl}_{3}$, and $\mathrm{C}_{2} \mathrm{Cl}_{4}$ using an Entech-Agilent GC-MS system operating in electron ionisation (EI) mode, as described in Leedham-Elvidge et al. (2015). Specifically, $1 \mathrm{~L}$ samples were dried and pre-concentrated before injection onto a $30 \mathrm{~m} \times 0.32 \mathrm{~mm}$ GS Gas Pro capillary column (Agilent); temperature was ramped from -10 to $200^{\circ} \mathrm{C}$. Samples were interspersed with repeated analyses of a working standard (SX-706070), a high-pressure air sample contained in a $34 \mathrm{~L}$ electropolished stainless steel cylinder (Essex Industries) provided by the Earth System Research Laboratory of the National Oceanic and Atmospheric Administration (NOAA-ESRL, Boulder, $\mathrm{CO}$, USA). $\mathrm{CH}_{2} \mathrm{Cl}_{2}, \mathrm{CHCl}_{3}$, and $\mathrm{C}_{2} \mathrm{Cl}_{4}$ were quantified on ions with a mass-to-charge ratio of $84\left(\mathrm{CH}_{2}^{35} \mathrm{Cl}_{2}^{+}\right), 83\left(\mathrm{CH}^{35} \mathrm{Cl}_{2}^{+}\right)$, and $166\left(\mathrm{C}_{2}^{35} \mathrm{Cl}_{3}^{37} \mathrm{Cl}^{+}\right)$respectively. Mean analytical precisions were $\pm 2 \%$ for $\mathrm{CH}_{2} \mathrm{Cl}_{2}$ and $\mathrm{C}_{2} \mathrm{Cl}_{4}$ and $\pm 3 \%$ for $\mathrm{CHCl}_{3}$. Instrument blanks, determined by analysing $1 \mathrm{~L}$ aliquots of high-purity nitrogen (BOC, research grade), were always below the detection limit of the instrument.

Some of the ground-based samples and a subset of the CARIBIC samples were also analysed for a range of halocarbons, including the newly identified $\mathrm{CH}_{2} \mathrm{ClCH}_{2} \mathrm{Cl}$, using a pre-concentration-GC system coupled to a Waters AutoSpec magnetic sector MS instrument, also operating in EI mode but run at a mass resolution of 1000 at $5 \%$ peak height. Samples (using between 200 and $250 \mathrm{~mL}$ of air) were analysed on an identical GS GasPro column following a previously described method (Laube et al., 2010, 2012; LeedhamElvidge et al., 2015). $\mathrm{CH}_{2} \mathrm{ClCH}_{2} \mathrm{Cl}$ was monitored on the ions with mass-to-charge ratios of $61.99\left(\mathrm{C}_{2} \mathrm{H}_{3}^{35} \mathrm{Cl}^{+}\right.$, qualifier) and $63.99\left(\mathrm{C}_{2} \mathrm{H}_{3}^{37} \mathrm{Cl}^{+}\right.$, quantifier). Mean analytical precision was $1.4 \%$ for $\mathrm{CH}_{2} \mathrm{ClCH}_{2} \mathrm{Cl}$ and the average blank signal was $0.07 \mathrm{ppt}$ (as quantified using regular measurements of research-grade helium) and was corrected for on a daily basis.

\subsection{Calibration and quality assurance}

$\mathrm{CH}_{2} \mathrm{Cl}_{2}, \mathrm{CHCl}_{3}$, and $\mathrm{C}_{2} \mathrm{Cl}_{4}$ data are reported on the latest (2003) calibration scales provided by NOAA-ESRL. As was shown in Leedham-Elvidge et al. (2015), our $\mathrm{CH}_{2} \mathrm{Cl}_{2}$ measurements compare very well with those of NOAA-ESRL at our mutual long-term sampling site at Cape Grim, Tasmania, over more than 6 years. As a recognised international calibration scale for $\mathrm{CH}_{2} \mathrm{ClCH}_{2} \mathrm{Cl}$ is not yet available, this compound was calibrated at UEA using the established static dilution technique recently described (Laube et al., 2012). $\mathrm{CH}_{2} \mathrm{ClCH}_{2} \mathrm{Cl}$ was obtained from Sigma Aldrich with a stated purity of $99.8 \%$. Three dilutions were prepared at 7.1, 11.9, and $15.8 \mathrm{ppt}$. The mixing ratio assigned to our working standard from these dilutions was $5.67 \mathrm{ppt}$ with a $1 \sigma$ standard deviation of $1.8 \%$. CFC-11 was added to the dilutions as an internal reference compound, and the $\mathrm{CFC}-11$ mixing ratios assigned to the working standard through these dilutions agreed with the value assigned by NOAA-ESRL within $4.3 \%$. This is well within the estimated uncertainty of the calibration system of $7 \%$ (Laube et al., 2012). In addition, the mixing ratios of $\mathrm{CH}_{2} \mathrm{ClCH}_{2} \mathrm{Cl}$ in the working standard were compared with those in three other high-pressure canisters (internal surface was either electropolished stainless steel or passivated aluminium) over the whole measurement period. The ratios between standards did not change within the $2 \sigma$ standard deviation of the measurements for any of the canisters analysed, indicating very good long-term stability for $\mathrm{CH}_{2} \mathrm{ClCH}_{2} \mathrm{Cl}$. This was also the case for $\mathrm{CHCl}_{3}$ and $\mathrm{C}_{2} \mathrm{Cl}_{4}$. As noted in Leedham-Elvidge et al. (2015), mixing ratios of $\mathrm{CH}_{2} \mathrm{Cl}_{2}$ were found to change over longer timescales in some of our standard canisters, but this drift has been successfully quantified and corrected for as indicated by the very good comparability with NOAA-ESRL measurements at the Cape Grim site noted above.

\section{Results}

Figure 1 shows the location of the three surface observation stations as well as the location of the CARIBIC samples. The aircraft sampling points have been coloured by their $\mathrm{CH}_{2} \mathrm{Cl}_{2}$ concentration (see later discussion). Data from the surface stations and from the CARIBIC aircraft flights are summarised in Table 1, together with a summary of published observations as reported in the most recent Scientific Assessment of Ozone Depletion (Carpenter et al., 2015). It should be noted that only selected samples were analysed for $\mathrm{CH}_{2} \mathrm{ClCH}_{2} \mathrm{Cl}$, and no data are available from Hengchun 2013 or from CARIBIC flights between Bangkok and Kuala Lumpur. In addition, only 16 Bachok samples were analysed for $\mathrm{CH}_{2} \mathrm{ClCH}_{2} \mathrm{Cl}$.

The highest concentrations of chlorinated VSLSs were measured in samples collected in Taiwan, suggesting that Taiwan is located relatively close to major emission regions. Figure 2 shows the March/April 2014 data from Cape Fuguei. The NAME model (see Supplement) can be used to infer the recent transport history of this pollution. Our NAME analysis (Fig. 2b-d) indicates that most of the samples that contained high concentrations of Cl-VSLSs had originated from regions to the north of Taiwan, primarily the East Asian mainland. The median sum of chlorine from the four VSLSs listed above ( $\Sigma \mathrm{Cl}_{\mathrm{VSLS}}$ ) in 22 samples collected at Cape Fuguei in March/April 2014 was 756 ppt (range 232- 
Table 1. Summary of Cl-VSLS data from the three surface stations and the seven CARIBIC flights. For comparison, the ranges reported in the most recent (2014) WMO ozone assessment (Carpenter et al., 2015) for the marine boundary layer (MBL) and lower tropical tropopause layer (TTL, 12-14 km altitude) are also shown. All data are reported as mole fractions (ppt). FRA: Frankfurt; BKK: Bangkok; KUL: Kuala Lumpur.

\begin{tabular}{|c|c|c|c|c|c|c|c|c|c|}
\hline & \multicolumn{2}{|c|}{ Taiwan 2013} & \multicolumn{2}{|c|}{ Taiwan 2014} & \multicolumn{3}{|c|}{ Bachok 2014} & \multicolumn{2}{|c|}{ MBL (WMO, 2014) } \\
\hline & Median & Range & Median & Range & $\operatorname{Median}(\mathrm{CS})^{\mathrm{a}}$ & Median (non-CS) & Range & Median & Range \\
\hline $\mathrm{CH}_{2} \mathrm{Cl}_{2}$ & 226.6 & $68-624$ & 227.4 & $70-639$ & 170.4 & 81.9 & $64.8-355$ & 28.4 & $21.8-34.4$ \\
\hline $\mathrm{CH}_{2} \mathrm{ClCH}_{2} \mathrm{Cl}$ & - & - & 85.4 & $16.7-309$ & 62.2 & 21.7 & $16.4-120^{\mathrm{c}}$ & 3.7 & $0.7-14.5^{\mathrm{d}}$ \\
\hline $\mathrm{CHCl}_{3}$ & 33.0 & $11.6-232$ & 35.1 & $13.8-103$ & 22.8 & 14.7 & $12.8-30.5$ & 7.5 & 7.3-7.8 \\
\hline $\mathrm{C}_{2} \mathrm{Cl}_{4}$ & 4.4 & $1.7-16.6$ & 5.5 & $1.7-18.6$ & 4.5 & 1.9 & $1.5-9.5$ & 1.3 & $0.8-1.7$ \\
\hline$\Sigma \mathrm{Cl}_{\text {VSLS }}$ & - & - & 755.8 & $232-2178$ & 546.0 & 243.1 & $207-1078^{c}$ & 93.4 & $70-134$ \\
\hline
\end{tabular}

\begin{tabular}{|c|c|c|c|c|c|c|c|c|}
\hline & \multicolumn{3}{|c|}{$\begin{array}{c}\text { CARIBIC (FRA-BKK, 65-97 E) } \\
10-12 \mathrm{~km}\end{array}$} & \multicolumn{3}{|c|}{$\begin{array}{l}\left.\text { CARIBIC (BKK-KUL, } 100-105^{\circ} \mathrm{E}\right) \\
10-12 \mathrm{~km}\end{array}$} & \multicolumn{2}{|c|}{$\begin{array}{l}\text { Lower TTL (WMO, 2014) } \\
\text { 12-14 km }\end{array}$} \\
\hline & Mean & Median & Range & Mean & Median & Range & Mean & Range \\
\hline $\mathrm{CH}_{2} \mathrm{Cl}_{2}$ & 43.2 & 31.6 & $14.6-121$ & 50.4 & 46.5 & $22.5-100$ & 17.1 & $7.8-38.1$ \\
\hline $\mathrm{CH}_{2} \mathrm{ClCH}_{2} \mathrm{Cl}^{\mathrm{e}}$ & 9.9 & 6.1 & $0.4-29.1$ & - & - & - & 3.6 & $0.8-7.0$ \\
\hline $\mathrm{CHCl}_{3}$ & 7.0 & 6.0 & $2.0-15.6$ & 9.3 & 8.7 & $3.7-46.6$ & 6.8 & $5.3-8.2$ \\
\hline $\mathrm{C}_{2} \mathrm{Cl}_{4}$ & 0.87 & 0.65 & $0.1-4.4$ & 1.6 & 1.5 & $0.2-5.9$ & 1.1 & $0.7-1.3$ \\
\hline$\Sigma \mathrm{Cl}_{\mathrm{VSLS}}{ }^{\mathrm{e}}$ & 153.7 & 119.3 & $48.4-330$ & & & & 67 & $36-103$ \\
\hline$\Sigma \mathrm{Cl}_{\mathrm{VSLS}} *^{\mathrm{f}}$ & 110.9 & 81.4 & $35.2-301$ & 134.8 & 127.8 & $56.6-251$ & - & - \\
\hline
\end{tabular}

${ }^{\mathrm{a}} \mathrm{CS}$ and non-CS refer to the cold surge (polluted) and non-cold surge periods at Bachok. ${ }^{\mathrm{b}}$ The WMO data are a compilation of all reported global measurements up to, and including, the year 2012. The range represents the smallest mean minus 1 standard deviation and the largest mean plus 1 standard deviation of all considered datasets. Data from the TTL were derived from various aircraft and balloon campaigns. ${ }^{\mathrm{c}} \mathrm{CH}_{2} \mathrm{ClCH}_{2} \mathrm{Cl}$ was only analysed for in 16 of the 28 samples collected at Bachok. ${ }^{\mathrm{d}}$ Note that the $\mathrm{CH}_{2} \mathrm{ClCH}_{2} \mathrm{Cl}$ MBL data actually date back to the early 2000 s. No recent data were reported. ${ }^{\mathrm{e}} \mathrm{CH}_{2} \mathrm{ClCH}_{2} \mathrm{Cl}$ was only analysed for in selected samples from the Frankfurt-Bangkok flights and not in any samples collected during the Bangkok-Kuala Lumpur flights. These statistics are therefore based on a reduced number of samples on the FRA-BKK route ( 24 out of 98$).{ }^{\mathrm{f}} \mathrm{\Sigma} \mathrm{Cl}_{\mathrm{VSLS}} *$ is defined as the sum of Cl-VSLSs excluding the contribution from $\mathrm{CH}_{2} \mathrm{ClCH}_{2} \mathrm{Cl}$. Statistics are derived from all samples (98 FRA-BKK; 81 BKK-KUL).

$2178 \mathrm{ppt})$. Similarly high concentrations and variation were seen in the 21 samples collected at Hengchun in March/April 2013 (Fig. S1 in the Supplement). To put these concentrations in a global context, the total organic chlorine derived from all known source gases in the background troposphere (including CFCs, HCFCs (hydrochlorofluorocarbons), and longer-lived chlorocarbons) is currently around $3300 \mathrm{ppt}$, with a typical Cl-VSLS contribution in the remote marine boundary layer of approximately $3 \%$ (Carpenter et al., 2015). Of the four VSLSs measured, the two largest contributors to $\Sigma \mathrm{Cl}_{\mathrm{VSLS}}$ in Taiwan were $\mathrm{CH}_{2} \mathrm{Cl}_{2}(55-76 \%)$ and $\mathrm{CH}_{2} \mathrm{ClCH}_{2} \mathrm{Cl}(14-30 \%)$.

Figure 3 shows the Cl-VSLS data from 28 samples collected at Bachok, Malaysia, during the winter monsoon season in late January/early February 2014. During this phase of the East Asian monsoon the prevailing winds are from the north-east and, as described earlier, are often impacted by emissions further to the north, including from mainland China. As can be seen in Fig. 3, there was a 7-day period between 19 and 26 January when significantly enhanced concentrations of Cl-VSLSs were observed. During this period NAME back trajectories show air travelling from continental East Asia and across the South China Sea before arriving at Bachok. Three examples during this cold surge event are shown in Fig. 3b-d. These trajectories often pass over Taiwan and, in some instances, also over parts of Indochina where additional emissions could have been picked up. As in the Taiwan samples, $\mathrm{CH}_{2} \mathrm{Cl}_{2}$ is the largest contributor to $\Sigma \mathrm{Cl}_{\text {VSLS }}$ (59-66\%), having a mean concentration of $179.9 \pm 71.9 \mathrm{ppt}$ (range 94.0-354.9 ppt, nine samples) during the 7-day period of the pollution event. The mean concentration of $\mathrm{CH}_{2} \mathrm{ClCH}_{2} \mathrm{Cl}$ was $64.4 \pm 23.9$ ppt (range 30.2 $119.5 \mathrm{ppt}$ ), accounting for $19-23 \%$ of $\Sigma$ ClvsLs. These abundances are substantially higher than those typically found in the marine boundary layer. For example, the range of $\Sigma \mathrm{Cl}_{\text {VSLS }}$ from the four compounds listed above in the tropical marine boundary layer reported in WMO (2014) is 70$134 \mathrm{ppt}$. The range observed at Bachok over the entire sampling period was $207-1078 \mathrm{ppt}$, with medians of $546 \mathrm{ppt}$ and 243 ppt during the polluted (20-26 January) and lesspolluted (27 January-5 February) periods respectively (see Table 1). It is interesting to note that even in the period after the cold surge event (Fig. 3e, f), the levels of Cl-VSLSs are still significantly higher than would be expected, suggesting that this region of the South China Sea is widely impacted by emissions from E Asia.

The pollution or "cold surge" event observed at Bachok lasted for 6-7 days and the back trajectories shown in Fig. 3 are typical of those arriving at Bachok during the winter monsoon period (see NAME animations in Supplement). To further investigate the frequency and typical duration of these events, a NAME trajectory analysis using carbon monoxide (CO) as a tracer of industrial emissions from regions north of $20^{\circ} \mathrm{N}$ was conducted for the entire winter season (see Sup- 
(a)
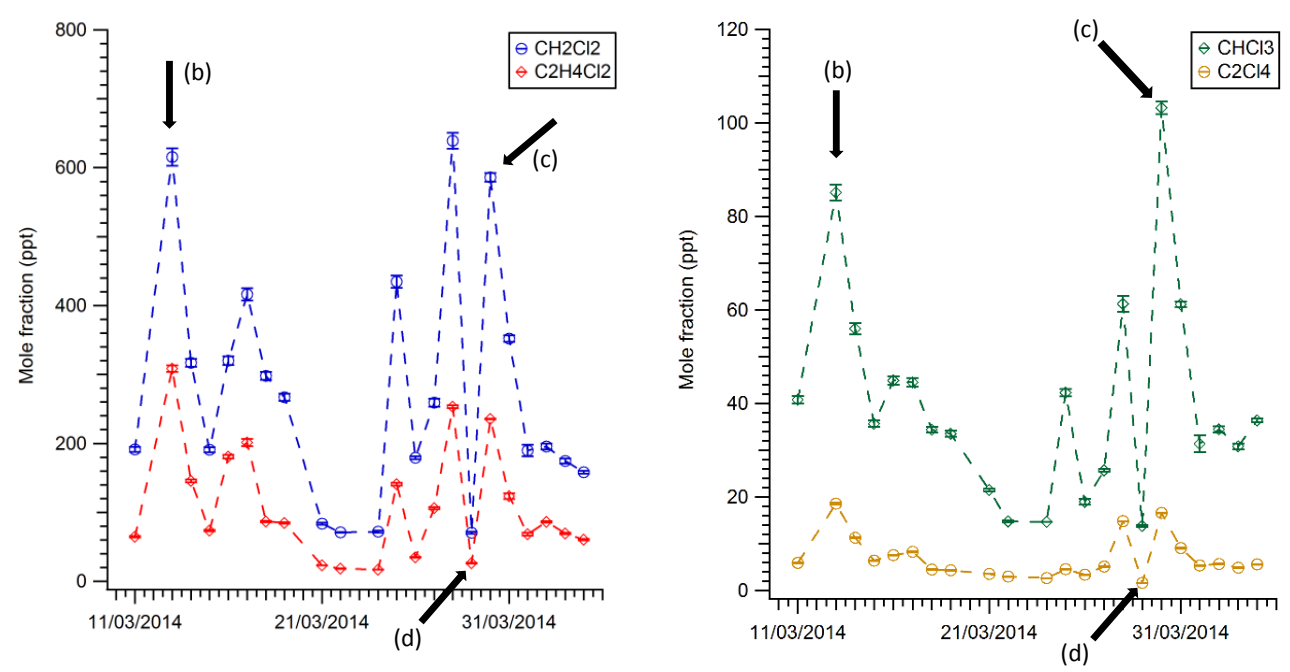

(b)

(c)

(d)

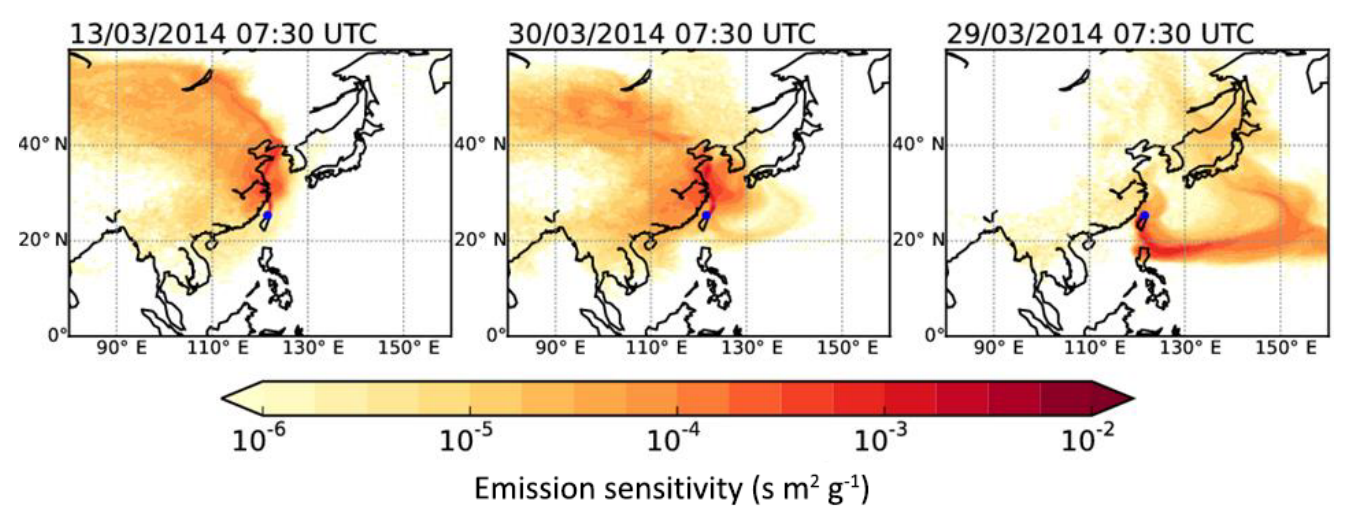

Figure 2. Upper panel (a): Mole fractions (ppt) of the four chlorinated VSLSs in air samples collected at Cape Fuguei, Taiwan, in March/April 2014. The error bars are \pm 1 standard deviation. The black arrows show the dates of the footprint maps shown below. Lower panel (bd): NAME footprint maps indicating the likely origin of the air sampled at Cape Fuguei. Panel (b), 13 March, and (c), 30 March, show examples where the observed VSLS levels are very high and suggest a strong influence from continental East Asia. Figure (d) is from 29 March where the influence of the mainland is much lower and the VSLS mole fractions are much closer to the expected background level. The location of Cape Fuguei is indicated with a blue circle (see also Fig. 1).

plement for details). Figure $4 \mathrm{a}$ shows a time series of this industrial CO tracer for winter 2013/2014 and suggests that the observed event in January, during which there was a strong correlation between the industrial $\mathrm{CO}$ tracer and $\mathrm{CH}_{2} \mathrm{Cl}_{2}$ (Fig. 4b), is likely to be repeated regularly throughout the winter. An analysis of a further five winters (Fig. 4c) demonstrates that 2013/2014 was not unusual and that the events depicted in Fig. 3a occur repeatedly every year (Fig. S2 in the Supplement).

The Bachok measurements clearly demonstrate the rapid long-range transport of highly elevated concentrations of Cl-VSLSs for several thousand kilometres across the South China Sea, as predicted by Ashfold et al. (2015). How- ever, to have an impact on stratospheric ozone, it is necessary to demonstrate that these high concentrations of $\mathrm{Cl}$ VSLSs can be rapidly lifted to the upper tropical troposphere (lower TTL) or above. Such evidence can be found in samples from several recent CARIBIC aircraft flights in the South East Asia region. Figure 1 shows significant enhancements of $\mathrm{CH}_{2} \mathrm{Cl}_{2}$ during flights over northern India and the Bay of Bengal and also between Bangkok and Kuala Lumpur. The same data are plotted against longitude in Fig. 5a, which shows that elevated concentrations were observed in the seven CARIBIC flights in the region during the periods December 2012-March 2013 and November 2013January 2014. The samples were collected in the altitude 
(a)
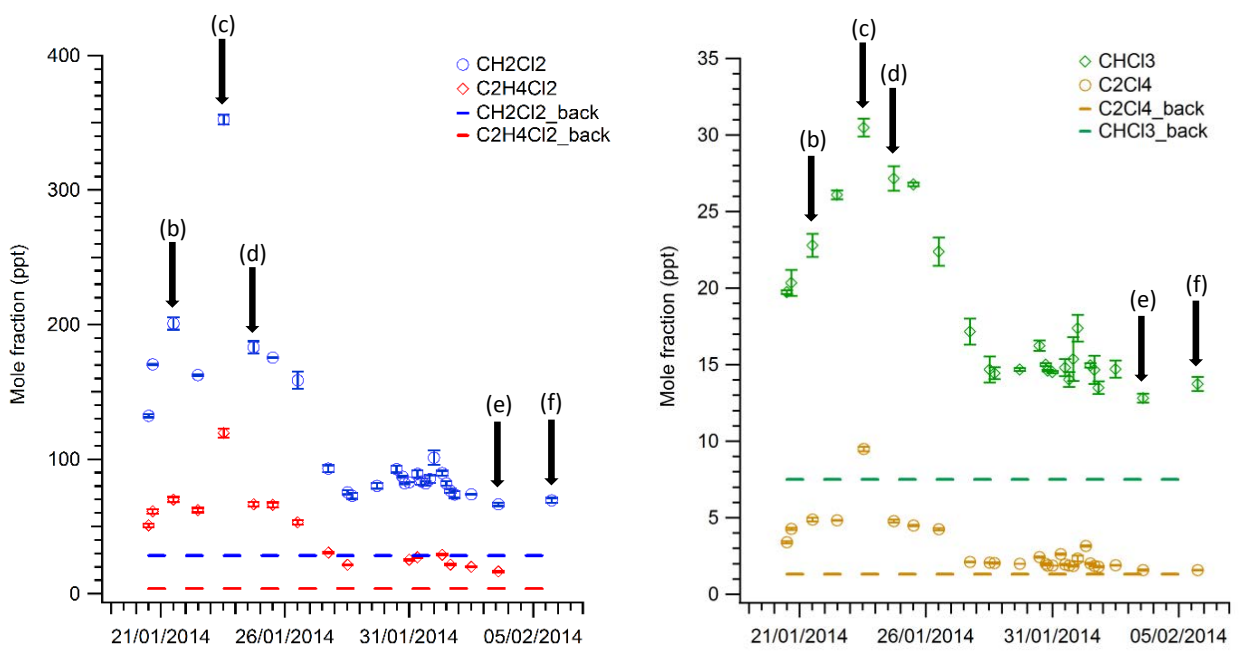

(b)

(c)

(d)

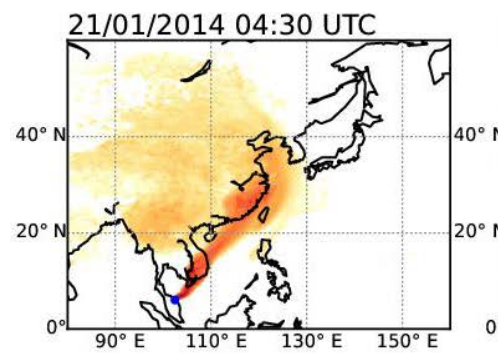

23/01/2014 04:30 UTC

24/01/2014 10:30 UTC

(e) 03/02/2014 07:30 UTC 05/02/2014 10:30 UTC

$(f)$

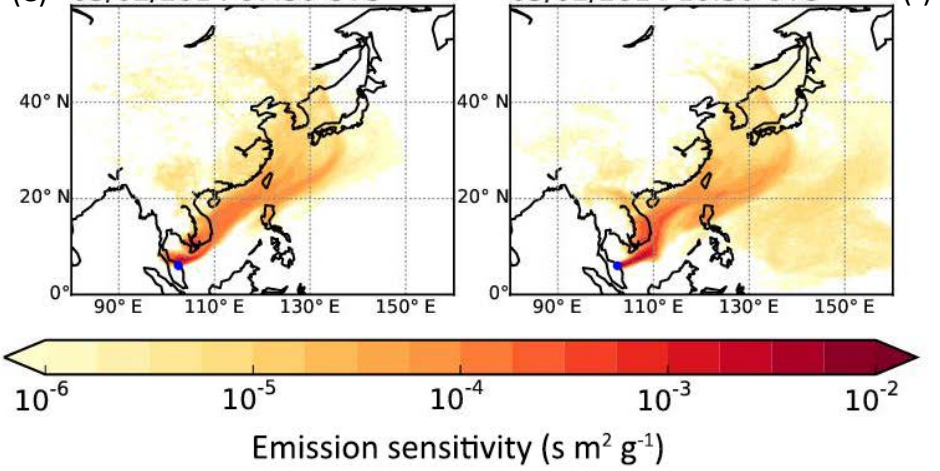

Figure 3. Panel (a): ole fractions (ppt) of the four chlorinated VSLSs in air samples collected at Bachok in January/February 2014. Strongly enhanced levels of all four compounds were seen for a 7-day period at the beginning of the campaign (20-26 January). Also shown (dashed line) are the approximate median background concentrations in the remote marine boundary layer in 2012 (from Carpenter et al., 2015). Lower panels (b-f): NAME footprint maps indicating the likely origin of the air sampled at Bachok. During the pollution episode (b: 21 January; c: 23 January; d: 24 January), the samples would have been heavily impacted by emissions from the East Asian mainland, whilst this influence is much reduced during the cleaner, non-polluted periods (e: 3 February; f: 5 February). Note that even after the main pollution event, the abundance of the VSLSs remain significantly above true background levels for much of the time, suggesting a widespread influence from industrial emissions on a regional scale. The location of Bachok is indicated with a blue circle (see also Fig. 1). 

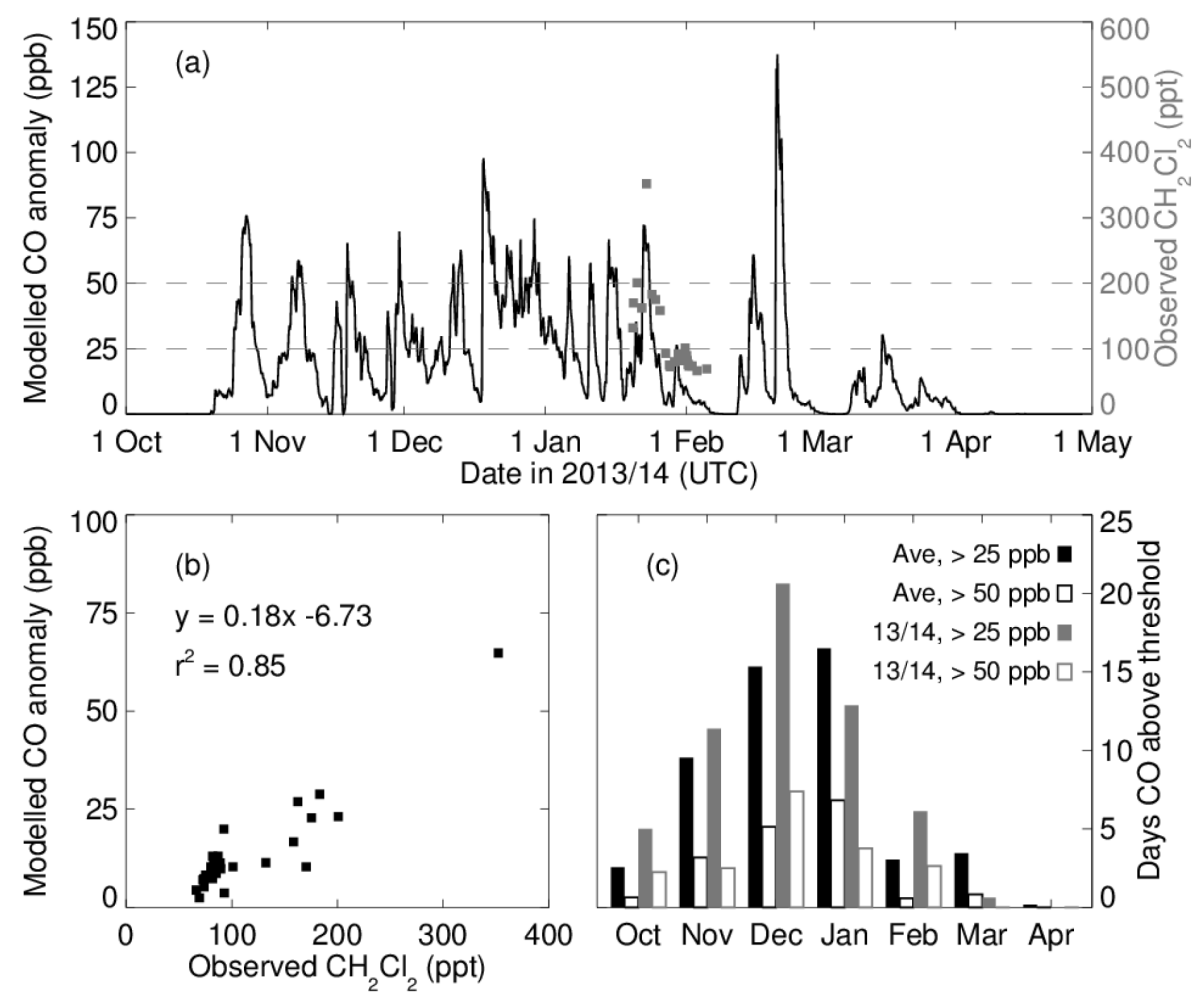

Figure 4. (a) Time series of the modelled carbon monoxide (CO) anomaly at Bachok (i.e. that due only to industrial emissions from north of $20^{\circ} \mathrm{N}$ in the previous 12 days) for winter 2013/2014. The $\mathrm{CH}_{2} \mathrm{Cl}_{2}$ data (grey squares) from the Bachok sampling period are overlaid. The dashed lines show the 25 and $50 \mathrm{ppb}$ thresholds referred to in Fig. 3c (see Supplement for further details). (b) Correlation of the modelled CO anomaly with the observed $\mathrm{CH}_{2} \mathrm{Cl}_{2}$. (c) Average number of days each month, averaged over six consecutive winters (2009/2010-2014/2015), where the modelled carbon monoxide anomaly at Bachok is above a particular threshold ( 25 and 50 ppb, which, from the regression in Fig. $3 \mathrm{~b}$, correspond to 176 and 315 ppt of $\mathrm{CH}_{2} \mathrm{Cl}_{2}$ ). The 2013/2014 winter is shown separately for comparison with the 6-year average.

range $10-12.3 \mathrm{~km}$, showing that recent industrial emissions can regularly reach the lower boundary of the TTL. Although $\mathrm{CH}_{2} \mathrm{ClCH}_{2} \mathrm{Cl}$ was only analysed for in a selection of samples during the flights from Germany to Bangkok, elevated mixing ratios coinciding with the high levels of $\mathrm{CH}_{2} \mathrm{Cl}_{2}$ were clearly observed (Fig. 5b). $\mathrm{CHCl}_{3}$ and $\mathrm{C}_{2} \mathrm{Cl}_{4}$ were also enhanced during these flights (Table 1), with $\Sigma \mathrm{Cl}_{\mathrm{VSLS}}$ being in the range of $48-330 \mathrm{ppt}$ (Fig. 5c). This is up to 3.2 times higher than that previously found in the lower TTL (36103 ppt; Carpenter et al., 2015). The highest abundances of Cl-VSLSs were seen in samples collected over the Bay of Bengal and on flights between Bangkok and Kuala Lumpur (Fig. 5a). NAME back trajectories (Fig. 5d) indicate that in these cases the sampled air had almost always been transported from the east and had often been impacted by emissions from East Asia, with possible contributions from other countries including the Philippines, Malaysia, and Indochina.

\section{Discussion}

The high mixing ratios of $\mathrm{CH}_{2} \mathrm{Cl}_{2}$ observed in the Taiwan samples are not entirely unexpected. Previous studies have found very high levels ( $>1 \mathrm{ppb}$ ) of $\mathrm{CH}_{2} \mathrm{Cl}_{2}$ in various Chinese cities (Barletta et al., 2006) and in the Pearl River Delta region (Shao et al., 2011). Elevated levels (several hundred ppt) were also observed in aircraft measurements in polluted air emanating from China during the TRACEP campaign in 2001 (Barletta et al., 2006). These studies took place in the early 2000s, and emissions may be expected to have grown significantly since. $\mathrm{CH}_{2} \mathrm{Cl}_{2}$ is predominantly $(\sim 90 \%)$ anthropogenic in origin and is widely used as a chemical solvent, a paint stripper, and as a degreasing agent (McCulloch and Midgely, 1996; Montzka et al., 2011). Other uses include foam blowing and agricultural fumigation. A growing use of $\mathrm{CH}_{2} \mathrm{CL}_{2}$ is in the production of HFC-32 $\left(\mathrm{CH}_{2} \mathrm{~F}_{2}\right)$, an ozone-friendly replacement for HCFC$22\left(\mathrm{CHF}_{2} \mathrm{Cl}\right)$ in refrigeration applications. Around $10 \%$ of global $\mathrm{CH}_{2} \mathrm{Cl}_{2}$ emissions comes from natural marine and biomass burning sources (Simmonds et al., 2006; Montzka et al., 2011).

Whilst the strong enhancements of $\mathrm{CH}_{2} \mathrm{Cl}_{2}$ are not entirely unexpected, the presence of high concentrations of $\mathrm{CH}_{2} \mathrm{ClCH}_{2} \mathrm{Cl}$ most certainly are. There are very few previously reported measurements of $\mathrm{CH}_{2} \mathrm{ClCH}_{2} \mathrm{Cl}$, particularly 
(a)

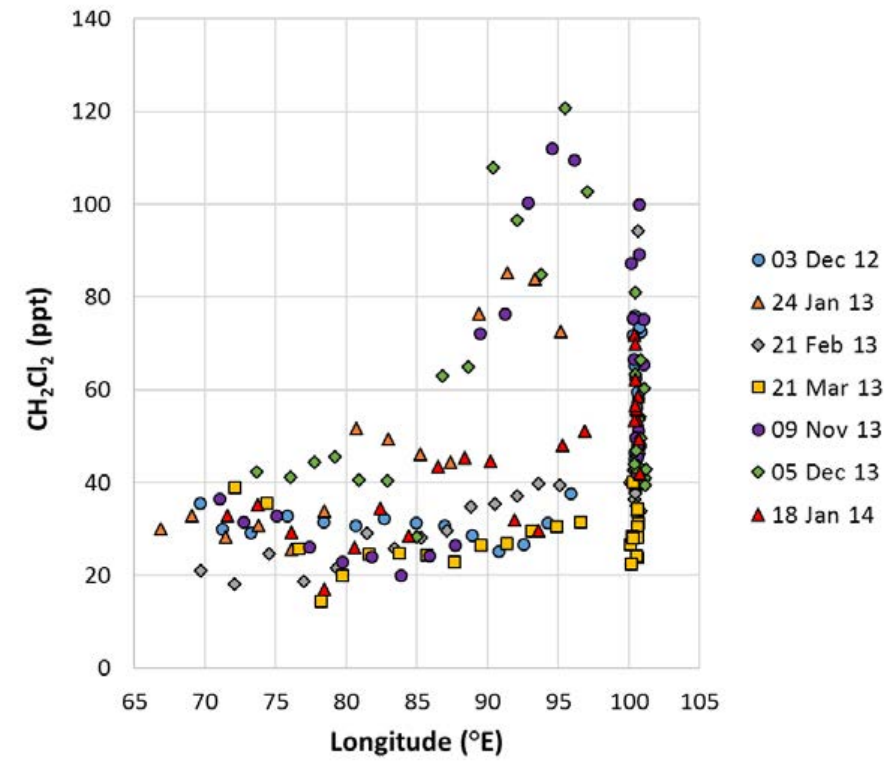

(d)

(b)

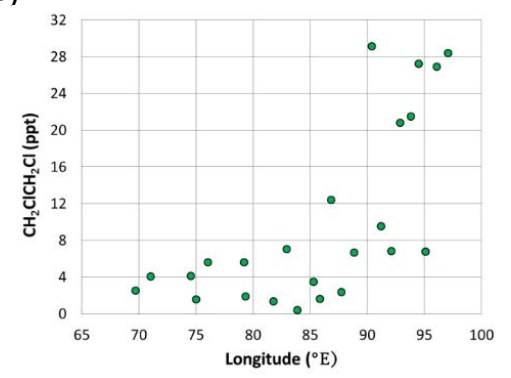

(c)

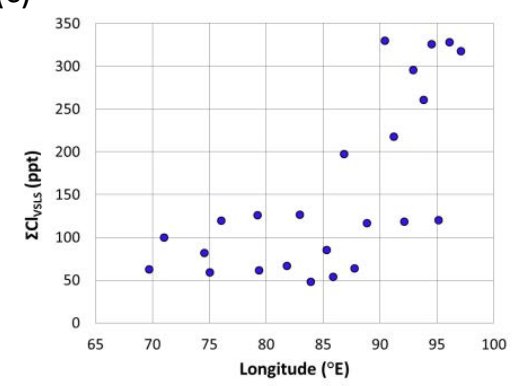

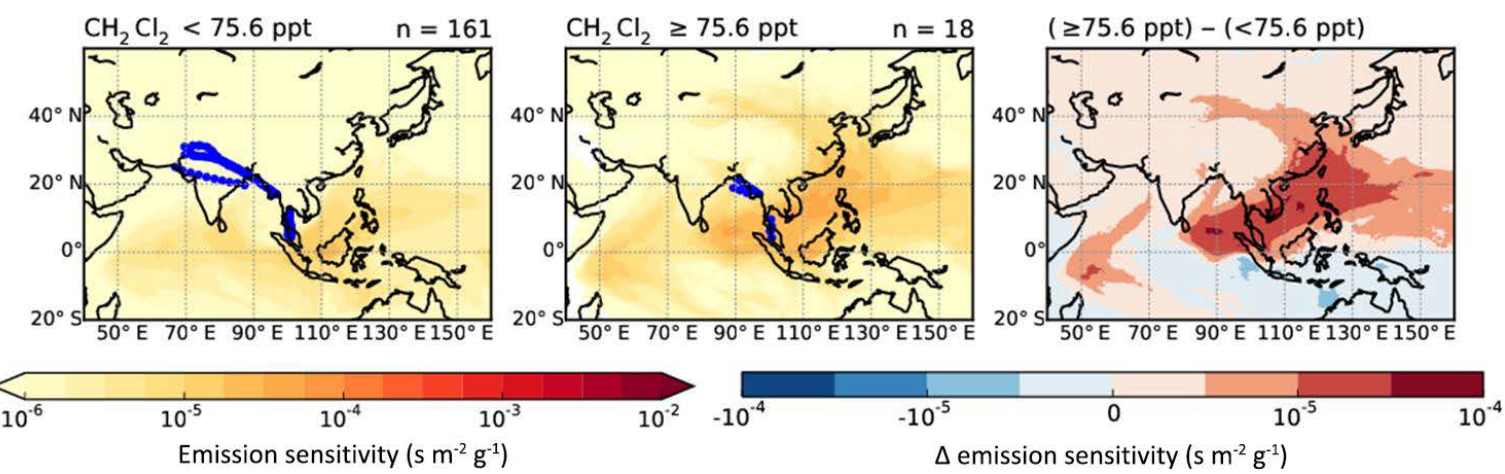

Figure 5. (a) Mole fractions (ppt) of $\mathrm{CH}_{2} \mathrm{Cl}_{2}$ in CARIBIC air samples collected at 10-12 km altitude over northern India, the Bay of Bengal, and SE Asia. The samples are plotted against longitude and have been coloured by date. (b) Mole fraction $(\mathrm{ppt})$ of $\mathrm{CH}_{2} \mathrm{ClCH} \mathrm{Cl}_{2}$ in selected CARIBIC samples (note: $\mathrm{CH}_{2} \mathrm{ClCH}_{2} \mathrm{Cl}$ was not monitored in the samples collected between Bangkok and Kuala Lumpur and only in a selection of samples on the Frankfurt-Bangkok route). (c) Total Cl-VSLSs derived from the four compounds of interest in the CARIBIC samples (note: total Cl-VSLSs could only be calculated for the samples shown in b above). (d) NAME footprint maps indicating the likely origin of the air sampled by the CARIBIC aircraft. NAME footprints at this altitude, and particularly in regions of strong sub-grid-scale convection not captured fully in the gridded meteorological input data, may be less reliable than those at the surface sites. This makes pinpointing particular emission regions more difficult. The central panel therefore shows a composite footprint derived from the samples that contained the highest levels of $\mathrm{CH}_{2} \mathrm{Cl}_{2}$ (90th percentile, $\left[\mathrm{CH}_{2} \mathrm{Cl}_{2}\right]>75.6 \mathrm{ppt}$ ), with the composite footprint from the remaining samples $\left(\left[\mathrm{CH}_{2} \mathrm{Cl}_{2}\right]<75.6 \mathrm{ppt}\right)$ shown in the left-hand panel. To emphasise the likely source regions the right-hand panel shows the difference between the middle and left-hand panels. The geographical location of each sample included in the composite analysis is shown in blue circles. 
in recent years. Elevated levels have been observed in urban environments close to known emission sources (Singh et al., 1981), and, more recently, Xue et al. (2011) reported elevated levels $(91 \pm 79 \mathrm{ppt})$ in air samples collected in the boundary layer over north-eastern China in 2007. The few reported measurements of $\mathrm{CH}_{2} \mathrm{ClCH}_{2} \mathrm{Cl}$ in the remote marine boundary layer are typically in the low ppt range (see Table 1), but these were mostly made well over a decade ago. No longterm atmospheric measurements of $\mathrm{CH}_{2} \mathrm{ClCH}_{2} \mathrm{Cl}$ have been reported, and $\mathrm{CH}_{2} \mathrm{ClCH}_{2} \mathrm{Cl}$ is not reported by the main surface monitoring networks (AGAGE and NOAA), so current background concentrations and longer-term trends are unknown. $\mathrm{CH}_{2} \mathrm{ClCH}_{2} \mathrm{Cl}$ is predominantly anthropogenic in origin, its primary use being in the manufacture of vinyl chloride, the precursor to polyvinyl chloride (PVC), and a number of chlorinated solvents. $\mathrm{CH}_{2} \mathrm{ClCH}_{2} \mathrm{Cl}$ also finds use as a solvent and a dispersant and has historically been added to leaded petrol as a lead scavenger (EPA, 1984). In common with $\mathrm{CH}_{2} \mathrm{Cl}_{2}$, it has also been used as a cleaning/degreasing agent and as a fumigant. China is the world's largest producer of PVC, accounting for $27 \%$ of global production in 2009 (DCE, 2017). Production has increased rapidly in recent years (14\% per year over the period 2000-2009; DCE, 2017), which could potentially have led to increased atmospheric emissions of $\mathrm{CH}_{2} \mathrm{ClCH}_{2} \mathrm{Cl}$. Simpson et al. (2011) observed a small enhancement in $\mathrm{CH}_{2} \mathrm{ClCH}_{2} \mathrm{Cl}$ in Canadian boreal forest fire plumes (background average, JuneJuly $2008,9.9 \pm 0.3 \mathrm{ppt}$; plume average $10.6 \pm 0.3 \mathrm{ppt}$ ) and estimated a global boreal fire source of $0.23 \pm 0.19$ kilotonnes $(\mathrm{kt}) \mathrm{yr}^{-1}$.

The other Cl-VSLSs presented here are $\mathrm{C}_{2} \mathrm{Cl}_{4}$ and $\mathrm{CHCl}_{3}$. In contrast to $\mathrm{CH}_{2} \mathrm{ClCH}_{2} \mathrm{Cl}$, long-term atmospheric data records are available for these compounds, although there are few data from the SE Asia region. Current trends show that $\mathrm{C}_{2} \mathrm{Cl}_{4}$ is declining in the background troposphere $\left(\sim 6 \% \mathrm{yr}^{-1}\right)$, whilst $\mathrm{CHCl}_{3}$ is approximately constant (Carpenter et al., 2015). However, both compounds were elevated in the samples containing high concentrations of $\mathrm{CH}_{2} \mathrm{Cl}_{2}$ and $\mathrm{CH}_{2} \mathrm{ClCH}_{2} \mathrm{Cl}$, suggesting that significant, co-located sources remain. Like $\mathrm{CH}_{2} \mathrm{ClCH}_{2} \mathrm{Cl}, \mathrm{C}_{2} \mathrm{Cl}_{4}$ is almost exclusively anthropogenic in origin, used primarily as a solvent in the dry-cleaning industry, as a metal degreasing agent, and as a chemical intermediate, for example in the manufacture of the hydrofluorocarbons HFC-134a and HFC-125. $\mathrm{CHCl}_{3}$ is believed to be largely natural in origin (seawater, soils, macroalgae), but potential anthropogenic sources include the pulp and paper industry, water treatment facilities, and HFC production (McCulloch, 2003; Worton et al., 2006; Montzka et al., 2011).

\subsection{Regional emissions of $\mathrm{CH}_{2} \mathrm{Cl}_{2}$ and $\mathrm{CH}_{2} \mathrm{ClCH}_{2} \mathrm{Cl}$}

China does not report production or emission figures for $\mathrm{CH}_{2} \mathrm{Cl}_{2}$. However, emissions of $\mathrm{CH}_{2} \mathrm{Cl}_{2}$ can be estimated from the known Chinese production of HCFC-22 $\left(\mathrm{CHClF}_{2}\right)$.
This is possible because the production of $\mathrm{HCFC}-22$ requires $\mathrm{CHCl}_{3}$ as feedstock ( $1 \mathrm{~kg} \mathrm{HCFC}-22$ requires $1.5 \mathrm{~kg} \mathrm{CHCl}_{3}$ ) and because $\mathrm{CHCl}_{3}$ is produced almost entirely (>99\%) for HCFC-22 production. Production of chloromethanes by any manufacturing process leads to the inevitable co-production of $\mathrm{CH}_{2} \mathrm{Cl}_{2}$ and $\mathrm{CHCl}_{3}$, with smaller (3-5\%) co-production of carbon tetrachloride $\left(\mathrm{CCl}_{4}\right)$. The production ratios vary by individual plant but are within the range of $30: 70-70: 30$ (\% $\mathrm{CH}_{2} \mathrm{Cl}_{2}: \mathrm{CHCl}_{3}$ ). Chinese chloromethanes plants, which together represent some $60 \%$ of global capacity and production, are generally built to a $40: 60-60: 40$ flexibility ratio. With falling $\mathrm{CHCl}_{3}$ demand due to diminished feedstock demand for HCFC-22 production, and based on regular discussions with the individual large producers, ratios in China have been switching in recent years from the traditional $40: 60$ towards $50: 50\left(\mathrm{CH}_{2} \mathrm{Cl}_{2}: \mathrm{CHCl}_{3}\right.$; Nolan Sherry associates $^{1}$ ).

It can be calculated that in 2015 China produced approximately $600 \mathrm{kt}$ of HCFC-22 for all uses (Nolan Sherry associates), which would require $900 \mathrm{kt}$ of $\mathrm{CHCl}_{3}$ as feedstock. Subtracting Chinese imports of $\mathrm{CHCl}_{3}$ (40 kt; Comtrade, 2016) and allowing for some limited emissive solvent use (15kt) suggests that China produced around $875 \mathrm{kt}$ of $\mathrm{CHCl}_{3}$ in 2015. As noted above, in the chlorocarbon industry, $\mathrm{CH}_{2} \mathrm{Cl}_{2}$ and $\mathrm{CHCl}_{3}$ are produced in the same manufacturing process, and in China this is currently moving from a historic production ratio of around $40: 60$ towards $50: 50$. Using a production ratio of $45: 55$, it can therefore be estimated that China produced around $715 \mathrm{kt}$ of $\mathrm{CH}_{2} \mathrm{Cl}_{2}$ in 2015. Approximately $90 \mathrm{kt}$ of this was exported (Comtrade, 2016), and another $170 \mathrm{kt}$ was used for the production of HFC-32 $\left(\mathrm{CH}_{2} \mathrm{~F}_{2}\right)$, which is a non-emissive application (Nolan Sherry associates). This leaves an estimated $455 \mathrm{kt}( \pm 10 \%)$ of $\mathrm{CH}_{2} \mathrm{Cl}_{2}$ which is used almost exclusively in emissive applications such as paint stripping, foam blowing, pharmaceuticals, and solvent use. Although there is no specific industry-based aggregation of these numbers, they have been verified in discussion with Chinese and other industry sources. A similar method has recently been used to assess emissions of $\mathrm{CCl}_{4}$ (SPARC, 2016).

There is a strong linear correlation between the observed $\mathrm{CH}_{2} \mathrm{Cl}_{2}$ and $\mathrm{CH}_{2} \mathrm{ClCH}_{2} \mathrm{Cl}$ data at both Bachok $\left(R^{2}=\right.$

\footnotetext{
${ }^{1}$ Nolan Sherry Associates (NSA) proprietary information: some of the data used in these calculations are proprietary in nature, being based on direct information from discussions with the producers, and have been aggregated for reasons of confidentiality. In the case of the HCFC-22 production data this is also because there are two uses of HCFC22: as a chemical intermediate, and as a refrigerant and a foam blowing agent. The latter uses are "emissive" and are controlled by the Montreal Protocol (http://ozone.unep.org) and are in the public domain. Information on the controlled uses of HCFC22 may be found at http://ozone.unep.org or by access to the Multilateral Fund of the Montreal Protocol (http://www.multilateralfund. org) and, in the case of China, by private subscription to the industry magazine China Fluoride Materials (www.cnchemicals.com).
} 
0.9799) and Cape Fuguei $\left(R^{2}=0.9189\right)$. Combining the datasets yields a slope of $0.4456 \pm 0.0194\left(R^{2}=0.9228\right)$. Using the emissions for $\mathrm{CH}_{2} \mathrm{Cl}_{2}$ derived above (455 kt) and making the assumptions that (1) all emissions originate in China and (2) there are no significant relative losses in the two compounds since emission (lifetimes are 144 days for $\mathrm{CH}_{2} \mathrm{Cl}_{2}$ and 65 days for $\mathrm{CH}_{2} \mathrm{ClCH}_{2} \mathrm{Cl}$ ), we can estimate Chinese emissions of $\mathrm{CH}_{2} \mathrm{ClCH}_{2} \mathrm{Cl}$ to be of the order of $203 \pm 9 \mathrm{kt} \mathrm{yr}^{-1}$. If accurate, the scale of these emissions is a major surprise as $\mathrm{CH}_{2} \mathrm{ClCH}_{2} \mathrm{Cl}$ is highly toxic (suggesting that local emissions would be minimised) and believed to be used almost exclusively in non-emissive applications.

\section{Concluding remarks}

When calculating the VSLS contribution to stratospheric chlorine, it is usual to assume an average concentration in the region of the TTL known as the level of zero radiative heating (LZRH). The LZRH is located at the transition between clear-sky radiative cooling and clear-sky radiative heating. This occurs at an approximate altitude of $15 \mathrm{~km}$, and it is believed that air masses above this level will go on to enter the stratosphere (Carpenter et al., 2015). As noted above there are very few measurements in this region and, furthermore, many of the available measurements were made over a decade ago, and assumptions based on surface temporal trends have to be made in order to estimate present-day values (Carpenter et al., 2015; Hossaini et al., 2015a). Another key deficiency in this estimation of VSLS concentrations entering the stratosphere is that most of the reported measurements have not been made in the two key regions where the strongest troposphere-to-stratosphere transport occurs. Although we have no data from the region of the LZRH, the CARIBIC data over northern India and SE Asia suggest that the contribution of VSLSs to stratospheric chlorine loading may be significantly higher than is currently estimated (50-95 ppt; Carpenter et al., 2015). It is also interesting to note that the much-discussed contribution of VSLS-Br compounds to stratospheric bromine is approximately $5 \mathrm{ppt}$, which is equivalent to $300 \mathrm{ppt}$ of chlorine (1 ppt of bromine is roughly equivalent to $60 \mathrm{ppt}$ chlorine; Sinnhuber et al., 2009). The CARIBIC measurements suggest that Cl-VSLSs could currently, on occasion, contribute a similar amount.

These new measurements of Cl-VSLSs in Taiwan, in Malaysia, and from an aircraft flying above South East Asia show that there are substantial regional emissions of these compounds; that these emissions can be rapidly transported long distances into the deep tropics; and that an equally rapid vertical transport to the upper tropical troposphere is a regular occurrence. Although the focus of this paper is short-lived chlorinated gases, there are many other chemical pollutants contained in these air masses which will have a large impact on such things as regional air quality.
Unlike the bromine-containing VSLSs, which are largely natural in origin, the Cl-VSLSs reported here are mainly anthropogenic, and consequently it would be possible to control their production and/or release to the atmosphere. Of particular concern are the rapidly growing emissions of $\mathrm{CH}_{2} \mathrm{Cl}_{2}$, and potentially $\mathrm{CH}_{2} \mathrm{ClCH}_{2} \mathrm{Cl}$, especially when considering the geographical location of these emissions, close to the major uplift regions of the western Pacific (winter) and the Indian sub-continent (summer). Without a change in industrial practices, the contribution of Cl-VSLSs to stratospheric chlorine loading is likely to increase substantially in the coming years, thereby endangering some of the hard-won gains achieved, and anticipated, under the Montreal Protocol.

Data availability. The data form part of a larger halocarbon database that will be submitted to the UK Centre for Environmental Data Analysis (CEDA, www.ceda.ac.uk) archive in 2018. Until this time, the data are available from the corresponding author upon request.

\section{The Supplement related to this article is available online at https://doi.org/10.5194/acp-17-11929-2017- supplement.}

Competing interests. The authors declare that they have no conflict of interest.

Acknowledgements. The authors would like to thank our CARIBIC project partners and the CARIBIC technical team (in particular Claus Koeppel, Dieter Scharffe). The Malaysia and Taiwan activities were funded through the UK Natural Environment Research Council (NERC) International Opportunities Fund (NE/J016012/1, NE/J016047/1, NE/N006836/1). CARIBIC has become part of IAGOS (www.IAGOS.org) and is supported by the German Ministry of Education and Science and Lufthansa. The CARIBIC halocarbon measurements were part-funded by the European FP7 project SHIVA (226224). UM-BMRS is supported by the Malaysian Ministry of Higher Education (Grant MOHE-HICoE IOES-2014). The sampling at Hengchun and Fuguei Cape was operated under the Seven South East Asian Studies (7-SEAS) program and funded by Taiwan EPA and MOST. Jia-Lin Wang and Lauren J. Gooch were funded through a NERC fellowship (NE/1021918/1) and studentship (NE/1210143) respectively. We acknowledge use of the NAME atmospheric dispersion model and associated NWP meteorological datasets made available to us by the UK Met Office. We also acknowledge the significant storage resources and analysis facilities made available to us on JASMIN by STFC CEDA along with the corresponding support teams.

Edited by: Anne Perring

Reviewed by: Bjoern-Martin Sinnhuber and one anonymous referee 


\section{References}

Ashfold, M. J., Pyle, J. A., Robinson, A. D., Meneguz, E., Nadzir, M. S. M., Phang, S. M., Samah, A. A., Ong, S., Ung, H. E., Peng, L. K., Yong, S. E., and Harris, N. R. P.: Rapid transport of East Asian pollution to the deep tropics, Atmos. Chem. Phys., 15, 3565-3573, https://doi.org/10.5194/acp-15-3565-2015, 2015.

Baker, A. K., Slemr, F., and Brenninkmeijer, C. A. M.: Analysis of non-methane hydrocarbons in air samples collected aboard the CARIBIC passenger aircraft, Atmos. Meas. Tech., 3, 311-321, https://doi.org/10.5194/amt-3-311-2010, 2010.

Barletta, B., Meinardi, S., Simpson, I. J., Rowland, F. S., Chan, C.Y., Wang, X., Zou, S., Chan, L. Y., and Blake, D. R.: Ambient halocarbon mixing ratios in 45 Chinese cities, Atmos. Environ., 40, 7706-7719, https://doi.org/10.1016/j.atmosenv.2006.08.039, 2006.

Bergman, J. W., Jensen, E. J., Pfister, L., and Yang, Q.: Seasonal differences of vertical-transport efficiency in the tropical tropopause layer: On the interplay between tropical deep convection, largescale vertical ascent, and horizontal circulations, J. Geophys. Res., 117, D05302, https://doi.org/10.1029/2011JD016992, 2012.

Brenninkmeijer, C. A. M., Crutzen, P., Boumard, F., Dauer, T., Dix, B., Ebinghaus, R., Filippi, D., Fischer, H., Franke, H., Frieß, U., Heintzenberg, J., Helleis, F., Hermann, M., Kock, H. H., Koeppel, C., Lelieveld, J., Leuenberger, M., Martinsson, B. G., Miemczyk, S., Moret, H. P., Nguyen, H. N., Nyfeler, P., Oram, D., O’Sullivan, D., Penkett, S., Platt, U., Pupek, M., Ramonet, M., Randa, B., Reichelt, M., Rhee, T. S., Rohwer, J., Rosenfeld, K., Scharffe, D., Schlager, H., Schumann, U., Slemr, F., Sprung, D., Stock, P., Thaler, R., Valentino, F., van Velthoven, P., Waibel, A., Wandel, A., Waschitschek, K., Wiedensohler, A., Xueref-Remy, I., Zahn, A., Zech, U., and Ziereis, H.: Civil Aircraft for the regular investigation of the atmosphere based on an instrumented container: The new CARIBIC system, Atmos. Chem. Phys., 7, 4953-4976, https://doi.org/10.5194/acp-7-4953-2007, 2007.

Brioude, J., Portmann, R. W., Daniel, J. S., Cooper, O. R., Frost, G. J., Rosenlof, K. H., Granier, C., Ravishankara, A. R., Montzka, S. A., and Stohl, A.: Variations in ozone depletion potentials of very short-lived substances with season and emission region, Geophys. Res. Lett., 37, L19804, https://doi.org/10.1029/2010GL044856, 2010.

Carpenter, L. J., Reimann, S., Burkholder, J. B., Clerbaux, C., Hall, B. D., Hossaini, R., Laube, J. C., and Yvon-Lewis, S. A.: Ozonedepleting substances (ODSs) and other gases of interest to the Montreal Protocol, chap. 1, in: Scientific Assessment of Ozone Depletion: 2014, Global Ozone Research and Monitoring Project - Report No. 55, World Meteorological Organization, Geneva, Switzerland, 2015.

Comtrade: available at: https://comtrade.un.org, last access: 25 May 2017.

DCE: Dalian Commodity Exchange website, PVC product guide, available at: http://www.dce.com.cn/DCE/Education/ MarketServices/Resources/1514180/index.html, last access: 24 May 2017.

Dorf, M., Butler, J. H., Butz, A., Camy-Peyret, C., Chipperfield, M. P., Kritten, L., Montzka, S. A., Simmes, B., Weidner, F., and Pfeilsticker, K.: Long-term observations of stratospheric bromine reveal slow down in growth, Geophys. Res. Lett., 33, L24803, https://doi.org/10.1029/2006GL027714, 2006.
EPA: Locating and estimating air emissions from sources of ethylene dichloride, Report of the United States Environmental Protection Agency, EPA-450/4-84-007d, March 1984.

Fueglistaler, S., Bonazzola, M., Haynes, P. H., and Peter, T.: Stratospheric water vapor predicted from the Lagrangian temperature history of air entering the stratosphere in the tropics, J. Geophys. Res., 110, D08107, https://doi.org/10.1029/2004JD005516, 2005.

Garreaud, R. D.: Subtropical cold surges: regional aspects and global distribution, Int. J. Climatol., 21, 1181-1197, 2001.

Haines, P. E. and Esler, J. G.: Determination of the source regions for surface to stratosphere transport: An Eulerian backtracking approach, Geophys. Res. Lett., 41, 1343-1349, https://doi.org/10.1002/2013GL058757, 2014.

Hegglin, M. I., Fahey, D. W., McFarland, M., Montzka, S. A., and Nash, E. R.: Twenty Questions and Answers About the Ozone Layer: 2014 Update, Scientific Assessment of Ozone Depletion: 2014, 84 pp., World Meteorological Organization, Geneva, Switzerland, 2015.

Hossaini, R., Chipperfield, M. P., Saiz-Lopez, A., Harrison, J. J., von Glasow, R., Sommariva, R., Atlas, E., Navarro, M., Montzka, S. A., Feng, W., Dhomse, S., Harth, C., Mühle, J., Lunder, C., O’Doherty, S., Young, D., Reimann, S., Vollmer, M. K., Krummel, P. B., and Bernarth, P. F.: Growth in stratospheric chlorine from short-lived chemicals not controlled by the Montreal Protocol, Geophys. Res. Lett., 42, 4573-4580, https://doi.org/10.1002/2015GL063783, 2015a.

Hossaini, R., Chipperfield, M. P., Montzka, S. A., Rap, A., Dhomse, S., and Feng, W.: Efficiency of short-lived halogens at influencing climate through depletion of stratospheric ozone, Nat. Geosci., 8, 186-190, https://doi.org/10.1038/ngeo2363, 2015b.

Laube, J. C., Martinerie, P., Witrant, E., Blunier, T., Schwander, J., Brenninkmeijer, C. A. M., Schuck, T. J., Bolder, M., Röckmann, T., van der Veen, C., Bönisch, H., Engel, A., Mills, G. P., Newland, M. J., Oram, D. E., Reeves, C. E., and Sturges, W. T.: Accelerating growth of HFC-227ea (1,1,1,2,3,3,3-heptafluoropropane) in the atmosphere, Atmos. Chem. Phys., 10, 5903-5910, https://doi.org/10.5194/acp-10-5903-2010, 2010.

Laube, J. C., Hogan, C., Newland, M. J., Mani, F. S., Fraser, P. J., Brenninkmeijer, C. A. M., Martinerie, P., Oram, D. E., Röckmann, T., Schwander, J., Witrant, E., Mills, G. P., Reeves, C. E., and Sturges, W. T.: Distributions, long term trends and emissions of four perfluorocarbons in remote parts of the atmosphere and firn air, Atmos. Chem. Phys., 12, 4081-4090, https://doi.org/10.5194/acp-12-4081-2012, 2012.

Law, K. S., Sturges, W. T., Blake, D. R., Blake, N. J., Burkholder, J. B., Butler, J. H., Cox, R. A., Haynes, P. H., Ko, M. K. W., Kreher, K., Mari, C., Pfeilsticker, K., Plane, J. M. C., Salawich, R. J., Schiller, C., Sinnhuber, B.-M., von Glasow, R., Warwick, N. J., Wuebbles, D. J., and Yvon-Lewis, S. A.: Halogenated very short lived substances, chap. 2, in: Scientific Assessment of Ozone Depletion: 2006, Global Ozone Research and Monitoring Project - Report No. 50, World Meteorological Organization, Geneva, Switzerland, 2007.

Leedham Elvidge, E. C., Oram, D. E., Laube, J. C., Baker, A. K., Montzka, S. A., Humphrey, S., O'Sullivan, D. A., and Brenninkmeijer, C. A. M.: Increasing concentrations of dichloromethane, $\mathrm{CH}_{2} \mathrm{Cl}_{2}$, inferred from CARIBIC air sam- 
ples collected 1998-2012, Atmos. Chem. Phys., 15, 1939-1958, https://doi.org/10.5194/acp-15-1939-2015, 2015.

McCulloch, A.: Chloroform in the environment: Occurrence, sources, sinks and effects, Chemosphere, 50, 1291-1308, https://doi.org/10.1016/S0045-6535(02)00697-5, 2003.

McCulloch, A. and Midgley, P. M.: The production and global distribution of emissions of trichlorothene, tetrachloroethene and dichloromethane over the period 1988-1992, Atmos. Environ., 30, 601-608, 1996.

Montzka, S. A., Reimann, S., Engel, A., Kruger, K., O’Doherty, S., and Sturges, W. T.: Ozone-depleting substances (ODSs) and related chemicals, chap. 1, in: Scientific Assessment of Ozone Depletion: 2010, Global Ozone Research and Monitoring Project - Report No. 52, World Meteorological Organization, Geneva, Switzerland, 2011.

Navarro, M. A., Atlas, E. L., Saiz-Lopez, A., Rodriguez-Lloveras, X., Kinnison, D. E., Lamarque, J.-F., Tilmes, S., Filus, M., Harris, N. R. P., Meneguz, E., Ashfold, M. J., Manning, A. J., Cuevas, C. A., Schauffler, S. M., and Donets, V.: Airborne measurements of organic bromine compounds in the Pacific tropical tropopause layer, P. Natl. Acad. Sci. USA, 112, 13789-13793, https://doi.org/10.1073/pnas.1511463112, 2015.

Pisso, I., Haynes, P. H., and Law, K. S.: Emission location dependent ozone depletion potentials for very short-lived halogenated species, Atmos. Chem. Phys., 10, 12025-12036, https://doi.org/10.5194/acp-10-12025-2010, 2010.

Randel, W. J., Park, M., Emmons, L., Kinnison, D., Bernarth, P., Walker, K. A., Boone, C., and Pumphrey, H.: Asian monsoon transport of pollution to the stratosphere, Science, 328, 611-613, https://doi.org/10.1126/science.1182274, 2010.

Sala, S., Bönisch, H., Keber, T., Oram, D. E., Mills, G., and Engel, A.: Deriving an atmospheric budget of total organic bromine using airborne in situ measurements from the western Pacific area during SHIVA, Atmos. Chem. Phys., 14, 6903-6923, https://doi.org/10.5194/acp-14-6903-2014, 2014.

Shao, M., Huang, D., Gu, D., Lu, S., Chang, C., and Wang, J.: Estimate of anthropogenic halocarbon emission based on measured ratio relative to $\mathrm{CO}$ in the Pearl River Delta region, China, Atmos. Chem. Phys., 11, 5011-5025, https://doi.org/10.5194/acp11-5011-2011, 2011.

Simmonds, P. G., Manning, A. J., Cunnold, D. M., McCulloch, A., O'Doherty, S., Derwent, R. G., Krummel, P. B., Fraser, P. J., Dunse, B., Porter, L. W., Wang, R. H. J., Greally, B. R., Miller, B. R., Salameh, P., Weiss, R. F., and Prinn, R. G.: Global trends, seasonal cycles, and European emissions of dichloromethane, trichloroethene, and tetrachloroethene from the AGAGE observations at Mace Head, Ireland, and Cape Grim, Tasmania, J. Geophys. Res., 111, D18304, https://doi.org/10.1029/2006JD007082, 2006.
Simpson, I. J., Akagi, S. K., Barletta, B., Blake, N. J., Choi, Y., Diskin, G. S., Fried, A., Fuelberg, H. E., Meinardi, S., Rowland, F. S., Vay, S. A., Weinheimer, A. J., Wennberg, P. O., Wiebring, P., Wisthaler, A., Yang, M., Yokelson, R. J., and Blake, D. R.: Boreal forest fire emissions in fresh Canadian smoke plumes: C1-C10 volatile organic compounds (VOCs), $\mathrm{CO}_{2}, \mathrm{CO}, \mathrm{NO}_{2}$, NO, HCN and CH3CN, Atmos. Chem. Phys., 11, 6445-6463, https://doi.org/10.5194/acp-11-6445-2011, 2011.

Singh, H. B., Salas, L. J., Smith, A. J., and Shigeishi, H.: Measurements of some potentially hazardous organic chemicals in urban environments, Atmos. Environ., 15, 601-612, 1981.

Sinnhuber, B.-M., Sheode, N., Sinnhuber, M., Chipperfield, M. P., and Feng, W.: The contribution of anthropogenic bromine emissions to past stratospheric ozone trends: a modelling study, Atmos. Chem. Phys., 9, 2863-2871, https://doi.org/10.5194/acp-92863-2009, 2009.

SPARC: SPARC Report on the Mystery of Carbon Tetrachloride, edited by: Liang, Q., Newman, P. A., and Reimann, S., SPARC Report No. 7, WCRP-13/2016, available at: www.sparc-climate. org/publications/sparc-reports/sparc-report-no7 (last access: 23 May 2017), 2016.

Worton, D. R., Sturges, W. T., Schwander, J., Mulvaney, R., Barnola, J.-M., and Chappellaz, J.: 20th century trends and budget implications of chloroform and related tri-and dihalomethanes inferred from firn air, Atmos. Chem. Phys., 6, 2847-2863, https://doi.org/10.5194/acp-6-2847-2006, 2006.

Xue, L., Wang, T., Simpson, I. J., Ding, A., Gao, J., Blake, D. R., Wang, X., Wang, W., Lei, H., and Jin, D.: Vertical distributions of non-methane hydrocarbons and halocarbons in the lower troposphere over northeast China, Atmos. Environ., 45, 6501-6509, 2011.

Zhang, Y., Sperber, K. R., and Boyle, J. S.: Climatology and interannual variation of the East Asian winter monsoon: Results from the 1979-95 NCEP/NCAR Reanalysis, Mon. Weather Rev., 125, 2605-2619, https://doi.org/10.1175/15200493(1997)125<2605:CAIVOT>2.0.CO;2, 1997. 